\title{
Teaching and learning in a multilingual Europe: findings from a cross-European study
}

\author{
J. E. Dockrell ${ }^{1} \cdot$ T. C. Papadopoulos ${ }^{2}$ - C. L. Mifsud ${ }^{3} \cdot$ L. Bourke $^{4} \cdot$ O. Vilageliu $^{5} \cdot$ \\ E. Bešić ${ }^{6}$ - S. Seifert ${ }^{6}$ - B. Gasteiger-Klicpera ${ }^{6}$ - A. Ralli ${ }^{7}$ - I. Dimakos ${ }^{8}$ - S. Karpava ${ }^{9}$. \\ M. Martins ${ }^{10} \cdot$ O. Sousa ${ }^{11}$ - S. Castro ${ }^{12}$ - H. B. Søndergaard Knudsen ${ }^{13}$ (D) P. Donau ${ }^{13}$. \\ B. Haznedar ${ }^{14} \cdot$ M. Mikulajová ${ }^{15} \cdot$ N. Gerdzhikova ${ }^{16}$
}

Received: 15 May 2020 / Revised: 14 December 2020 / Accepted: 16 December 2020 / Published online: 28 January 2021

(C) The Author(s) 2021, corrected publication 2023

\begin{abstract}
School classrooms within the EU are multilingual learning environments. The diversity of pupils in classrooms raises significant challenges for teachers, but to date, there are no data from large-scale surveys that compare views within and across European countries. A bespoke questionnaire was designed to examine views of current classroom learning environments with respect to the multilingualism. The questionnaire was piloted and subsequently completed by 2792 teachers across different European countries. Eleven countries provided sufficient data for analyses. Results from structural equation modelling showed that teachers' attitudes could be reliably measured across Europe with the use of carefully devised questionnaire, whose loading and factor structure remained invariant across countries. Teachers' views about multilingualism were most challenged by the numbers of children in their classes, not the percentage of multilingual pupils in the class. Countries differed in how they perceived multilingualism, with their differences leading to distinctive country clusters. Gender and education level (elementary vs. secondary) differences were also observed irrespective of country. These findings enhance our understanding of the role that the characteristics of teachers and their classrooms play in a multilingual setting across diverse European settings. The practical relevance of the results and new opportunities for teacher training are discussed.
\end{abstract}

Keywords Teaching $\cdot$ Learning $\cdot$ Schools $\cdot$ Multilingualism $\cdot$ Europe

The increased mobility in the last decades between EU countries with the combined immigration and numbers of refugees to the EU has resulted in rapid growth in both the numbers of

J. E. Dockrell

j.dockrell@ucl.ac.uk

Extended author information available on the last page of the article 
children raised multilingually and children who are being instructed in a language that is not their first language. Multilingual classrooms are now commonplace, with children speaking a wide range of first languages. For example, in England, over 1 in 5 children has English as an additional language (Strand et al. 2015). Schools, where a significant minority of pupils do not speak the language(s) of instruction at home, are now a frequent occurrence (OECD 2018). Many children are faced with learning and being assessed in the official language $(\mathrm{s})^{1}$ of education, and for many, there is a risk of underperforming. These students lag behind their native-born peers in most European education systems (Eurydice 2019). This is further exacerbated in many large urban settings where social disadvantage is compounded with high levels of children whose first language is not the language of instruction. Providing effective learning environments is key to the children's success but requires effective pedagogy, sensitive to the local multilingual context. A first step in understanding teaching and learning in these contexts is to map teachers' views and behaviours. To achieve this aim, a reliable measure to capture teachers' views and understanding is required and an examination of the contextual factors which impact these. To date, there has been no large-scale comparative quantitative study across European countries that has examined teachers' knowledge, attitudes and beliefs about the multilingual European education context. The current study aimed to develop a questionnaire to capture teachers' knowledge, attitudes and beliefs about multilingual education, explore differences across EU countries and identify variables that impacted the teachers' views.

\section{Background}

Government policies and institutions typically aim to maintain the use of a standardized form of the dominant language(s) (García and Hesson 2015). Teachers are often not trained in supporting L2 acquisition. In Portugal, for example, only $4 \%$ of primary school teachers and $16 \%$ of secondary school teachers have training in teaching an L2 (Madeira 2015). Social constraints, coupled with the fact that many teachers may not have the skills and support to adapt their classrooms and pedagogical approaches to the multilingual European reality, raise significant obstacles for pupils, teachers and policymakers.

Over recent years, EU policy has sought to broaden the choice of languages taught in schools to reflect the personal interests of learners and build on their linguistic capacities (European Commission 2015 p. 16). In parallel, researchers have sought to explore multilingual classroom contexts within specific countries using a range of qualitative and quantitative approaches. These studies provide rich and important data about both the settings of study and the local practices. To date, studies have been implemented on a small scale, in contexts which are bilingual or trilingual (e.g. Gogolin 2002; Kirsch 2018a; Linan-Thompson et al. 2018; Rosiers et al. 2018), or, when more extensive studies have been carried out, results are country specific (for France, see Mary and Young 2018; Young 2014; for Flanders, see Pulinx et al. 2017; Strobbe et al. 2017). These country- and context-specific studies raise important questions about whether the key factors identified generalize across European settings and can be used to inform policy and pedagogy more widely, highlighting the need for a comparative study.

Little is known about how the views of teachers working in multilingual classrooms differ across European countries and the different influences and barriers that inform practices. To gauge the nature and the extent of these challenges, a questionnaire for teachers was developed 
and distributed in 11 European countries. Our focus was on factors, which we hypothesized influence children in multilingual classrooms: teachers' experience and views of multilingualism, the impact of the pupil's first language on learning and acquisition of the L2 (their second language) and language learning opportunities. In the following sections, we evidence the importance of these factors.

\section{Teachers and classrooms}

The role teachers play in students' academic attainments and learning experiences is well documented. Once student variables are accounted for, teachers are the most significant factor in student achievement and well-being (Hattie 2009). The precise driver of this relationship is complicated (Seidel and Shavelson 2007) but includes variables such as teaching experience, subject knowledge, personality, motivation, gender and beliefs (see Hattie 2009, for a review). Teachers are reported to become more reflective, more knowledgeable and more effective with experience (Bahr and Mellor 2016) yet continue to be challenged by the numbers and diversity of pupils in their classes (Strobbe et al. 2017; Krueger 1999), often reflecting a monolingual ideology (Gogolin 2002). Of relevance to the current research is the evidence that pupil characteristics and classroom demographics also moderate teacher effects. The teacherstudent relationship for achievement is stronger for at-risk pupils, including ethnic minority students than for their non-disadvantaged peers (Bleses et al. 2018; Pianta et al. 2008). Importantly, in this context, intercultural openness impacts on both a close teacher-student relationship and more positive ethnic outgroup attitudes among majority students (Geerlings et al. 2018), potentially resulting in more effective learning environments (Strobbe et al. 2017).

Both quantitative and qualitative research have demonstrated how multilingual diversity in the classroom allows multilingual children to feel both socially and emotionally supported (Rosiers et al. 2018; Strobbe et al. 2017). However, the role of teacher characteristics in these multilingual classrooms (elementary and secondary) across European countries has not been examined. Given recent systematic reviews and meta-analyses (de Boer et al. 2018; Kim et al. 2019; Klassen and Kim 2019; Vandenbroucke et al. 2018), teachers' experiences and attitudes are likely to play a critical role in the educational lives of multilingual learners in Europe. To capture the dynamics of multilingual classrooms, both teacher views and the classroom learning context need to be explored.

\section{The pupils}

Children whose language is not the official language of instruction are a heterogeneous population, including migrants, refugees and children born in the country, but whose home language is different from the language of instruction. For many children, language status is highly correlated with socioeconomic status, where people born in a different country from the one in which they reside in the EU are twice as likely to suffer deprivation (Eurostat 2018). Children growing up in these contexts thus experience a double jeopardy of low language status and poverty (OECD 2018).

A variety of terms have been used to describe children's language status. These descriptors include L2 learners, immigrants, bilingual pupils, additional language learners and multilingual speakers. Each of these terms has slightly different denotations, although there is an overlap between the groups. For example, while many immigrants may not have secure access to the language of instruction, others will have more extensive knowledge; migrants to England from Malta, typically, have a good grasp of the English 
language. By analogy, bilingual pupils may or may not have both their languages used in the school context. In areas of Wales, both English and Welsh are the languages of instruction (Gathercole and Thomas 2009), and in Catalonia, both Spanish and Catalan are used in some schools (Kirsch 2018a, 2018b). By contrast, in Denmark, three different official languages are used in schools (Knudsen et al. 2020).

In a minority of cases, different languages are used in both curricular and noncurricular contexts (Rosiers et al. 2018). Overall first language use in these contexts is more common outside compulsory schooling and is often not part of the language of the classroom (Eurydice 2017). Some children, for example, in England, Greece, Italy, Portugal and Turkey, will be in virtually monolingual classroom settings. In contrast, others, such as those in Austria (German, Austro-Bavarian), Catalonia (Catalan and Spanish) or the Netherlands (Dutch and a range of regional languages) will have more diversity in the language settings. By contrast, in countries like Malta, the whole school population receives some form of bilingual education (García 2009), the languages of schooling are available in the wider out-of-school environment, and learners are in contact with both Maltese and English. In such cases of 'societal bilingualism' (Sebba 2010), bilingualism is at the level of social organization beyond the individual or nuclear family.

Moreover, within these different educational contexts, there will be a different emphasis on the importance of second language learning, and teachers will vary in their linguistic expertise. To begin to explore these differences, comparisons across countries are needed, comparisons that are informed by the local multilingual context. In the current paper, the term 'L2 learners' is used to refer to children whose home language is not the language(s) of instruction in the schools they attend, and we aim to capture the impact of these factors in the measure developed.

\section{Second language learning}

How we understand children's acquisition of the language of instruction, when it is not their home or first language, is the subject of debate, influences classroom pedagogy and varies between European countries. In an analogous fashion to first language learning, children need basic language nutrition (Zauche et al. 2016). How this is manifested in the classroom varies. Two pedagogical approaches can be identified. It has been argued that languages are learnt linearly and are best taught separately, in a 'parallel monolingualism' (Heller 1999). This approach highlighted the potential interference between languages, while ensuring that the learner has adequate opportunities to learn and use languages, including the use of complex vocabulary and grammatical constructions in a structured way. Such an approach is supported by evidence from parental language input patterns and children's bilingual use, where both use of the minority and majority language are important for children's success (De Houwer 2007). Alternative approaches have highlighted the dynamic interplay between languages and cultures (Mifsud and Vella 2018a). These approaches emphasize that multilingualism should be theorized as a legitimately shared repertoire of practice (Wenger 1998, p. 82), affecting the cultural identity, self-confidence and future employability of all the students. From this perspective, teachers should be empowered to reflect on their agency and how this is constrained by the structural ecologies surrounding them (Mifsud and Vella 2018a).

There is increasing evidence that children can draw on their multilingual repertoire to construct knowledge, develop their linguistic competence and mark their own identity (Kirsch 2018b). Yet there continues to be a tension between policy discourses, school practices, attitudes toward linguistic diversity and the research evidence (García 2009). Examining 
differences and drivers of differences across European countries provides an additional evidence-based framework for exploring these practices.

\section{Language learning opportunities}

There is increasing evidence that including first language instruction does not impede the learning of a second language (Tong et al. 2008). Meta-analyses from the USA (Rolstad et al. 2005) and within European contexts (Reljic et al. 2015) speak to the potential benefits of bilingual programmes. Rolstad et al. (2005) concluded that, in English-speaking contexts, bilingual education programmes are more effective in increasing both pupils' academic achievement and their native language. However, these studies typically involve countries with a large homogeneity of home languages (e.g. Spanish in the USA). Fewer studies exist within the European context where there is a significant diversity of home languages, although positive effects have been demonstrated for reading (Reljic et al. 2015). Overall, there is little, if any, evidence that the use of a child's home language in instructional contexts is problematic, and there are clear indications that this approach may be part of the solution to the challenges faced by second language learners. However, how such programmes can be operationalized varies on several dimensions, including whether they focus on content, language or multiple languages (see García 2009, for an overview), the diversity of L1s in the classroom (some of which may not have written forms) and teachers' lack of familiarity with these. To understand differences and similarities across European countries, it is important to capture teachers' understanding of the different approaches to multilingual use in their schools.

Teachers play a significant role in scaffolding children's learning, bringing objects and ideas to their attention and mediating the world for children to make it accessible to them. To facilitate and encourage language use, teachers can use language mediation strategies (Mifsud and Vella 2018b). However, to achieve this objective, teachers need to engage with language and cultural differences. There is evidence that cultural diversity is often treated in isolation in teacher training and not integrated across the curriculum (Civitillo et al. 2018), resulting in a lack of culturally responsive practices across subjects. Meeting the needs of diverse learners in schools and classrooms is challenging. Factors working against migrant children achieving their potential are reported to include a lack of resources, assessment tools, trained teachers and opportunities for pupils to develop their first language competencies to a higher level (Eurydice 2017). Furthermore, given the length of time to develop cognitive and academic proficiency in an L2 (Gathercole and Thomas 2009), there is a need for continuous language support over variable periods for children where the language of instruction is not their L1. The extent to which practices differ across European contexts is not clear.

\section{The present study}

To address the gap in our understanding of teachers' views of working in multilingual contexts across Europe, we (a) developed a bespoke questionnaire to explore European teachers views of learning in multilingual classrooms and established its fitness for purpose and (b) explored the views of teachers across 11 different European countries that participated in a European COST action (Work Group 1 of COST IS 1401, European Literacy Network). To capture different patterns of responses, we aimed to contrast teachers from countries where significant numbers of children did not have the language of instruction as their L1 and those with less linguistic diversity in their school 
populations. We expected that teachers' views of working with children from diverse linguistic backgrounds would be underpinned by their experience and understanding of multilingualism. Moreover, we predicted that language learning opportunities and the reported impact of the L2 would vary across countries (OECD 2018). We also explored teachers' ability to identify assessments and resources to support the teaching of children whose first/home language was not the language of instruction.

First, we established whether the questionnaire designed was fit for the purpose and captured teachers' views of working in multilingual classrooms across different European countries. We predicted that the questionnaire would capture the three dimensions which have been identified as important in multilingual education contexts that is teachers' views on multilingualism, the role of the first language of migrant children and views about L2 acquisition and its importance for Literacy. We then explored whether teachers' views were influenced by personal characteristics (age, gender, education level) or classroom contexts (number of pupils in their class and the percentage of multilingual pupils they taught). Finally, we explored whether countries differed in their teachers' views, reported practices and challenges. Our study aims to provide both a tool for use with teachers across Europe and preliminary comparative data across the European multilingual context.

\section{Methods}

\section{Participant countries}

We received data from 11 country sites, which are included in the analyses (see data management below). To benchmark the range in migrant population within our sample, brackets provide the percentage of foreign born population (data from 2019 EU census) as a proxy of population diversity. The 11 sites were Austria (19.4), Bulgaria (2.5), Catalonia (Spain, 13.9), Cyprus (21), Denmark (12.2), Greece (12.2), Malta (20), Portugal (19.3), Slovakia (3.6), Turkey $(3.77)^{2}$ and the UK (14.2). Data from Spain were only collected from Catalonia, a region in Spain with its autonomous department of education and where the language of instruction is primarily Catalan. Table 1 shows the participating countries and respondents by country.

\section{Questionnaire}

A bespoke questionnaire was designed for the study based on work by Mifsud \& Petrova (2017) as part of Work Group 1 of COST IS 1401 (European Literacy Network). Previous research was reviewed (e.g. De Angelis 2011; Ellis 2004; Haukås 2016; Lee and Oxelson 2006; Otwinowska 2014; Ramos 2009) and adapted items from De Angelis (2011) included. The questionnaire was refined following three consecutive focus group meetings with the COST steering group and a review of EU documents and current recommendations by governments to teach pupils in multilingual settings. The questionnaire was piloted with teachers in Malta and England, at which point amendments were made to clarify questions and extend open-ended options as required. The final Multilingual Questionnaire (MCQ) was then translated into local languages and backtranslated by individuals who were fluent in the local language of instruction and English. The questionnaire was created using SurveyMonkey ${ }^{\circledR}$ (https://www.surveymonkey.com/). 


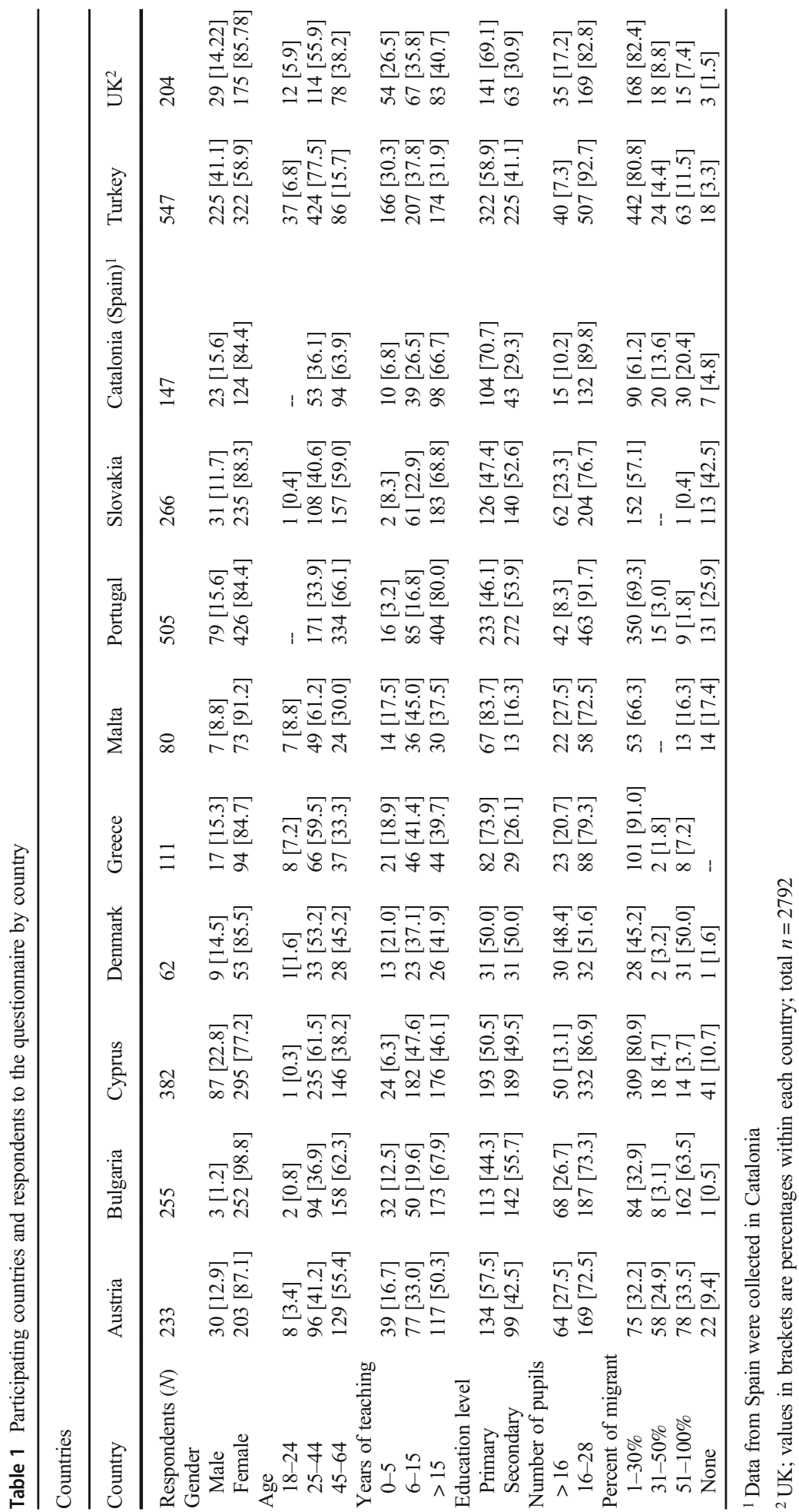


Completion of the questionnaire was voluntary, and countries were free to choose online completion, paper completion or a combination depending on the local context.

The final questionnaire consisted of eight sections: (1) demographic information about the respondents and their country of origin, (2) familiarity with other languages, (3) professional background, (4) information about teaching and learning in schools and classrooms, (5) views of multilingualism, (6) languages of migrant children and impact in the classroom, (7) acquisition of L2 (the language of instruction) and (8) literacy. The questionnaire comprised 77 items, of which 32 captured background details (Sections 1 to 4). Demographic and background information was presented using nominal categories. Items about learning and instruction were rated on a six-point Likert scale with 6 indicating that the respondent strongly agreed and 1 indicating that the respondent strongly disagreed. The questionnaire was preceded by an information sheet, which explained its purpose and defined key terms used in the questionnaire.

Reliability for all 31 items rated using a Likert scale was excellent (Cronbach's alpha .93). The range across countries was between .69 Catalonia (Spain) and .96 England, all in the good or above range. Subscales also demonstrated high reliability (Cronbach's Alpha): views on multilingualism .87, first language of migrant children .78, L2 acquisition .85 and literacy .90 .

\section{Participants' recruitment}

Each country was responsible for participant recruitment and used country-specific contacts, such as education departments. Online links to the questionnaire were distributed to primary and secondary schools, local authorities and colleges of education to capture as a representative sample of teachers as possible. In some settings, schools requested hard copies of the questionnaire, and these were distributed and collected from the relevant school offices.

Recruitment and promotion strategies were open, both at the level of countries and the participation of teachers per country. Survey countries were selected based on availability/ feasibility criteria, and individuals within each selected country were selected using random sampling in the case of large cohorts (e.g. Turkey) or participated in their entirety in the case of smaller cohorts (e.g. Denmark).

\section{Data cleaning and management}

The country lead partners were sent a preformatted SPSS data file to enter country-specific data. Countries were included if they had collected a minimum of 60 completed questionnaires. Where countries had collected more than 550 responses, cases were randomly selected to ensure data were not skewed by a single country. Missing data varied across countries, with eight of the 11 sites having less than $8 \%$ missing data points. For the remaining three countries, missing data were below $12 \%$, so the Expectation-Maximization (EM) algorithm imputation ${ }^{3}$ for all countries was applied.

\section{Results}

\section{Preliminary analysis}

Initially, we examined the factorability of the 45 items of the MCQ using Velicer's Minimum Average Partial test and Parallel Analysis to examine whether the number of four factors, 
namely, views on multilingualism (F1), first language of migrant children (F2), L2 acquisition (F3) and literacy (F4) was the appropriate number to retain (O'Connor 2000). Velicer's MAP test recommended a five-factor solution, the Parallel Analysis recommended a four-factor solution for the MCQ items, and the scree plot indicated a four-factor solution too. When comparing the five-factor solution to the four-factor solution, double-loading of items was an issue in each solution; however, the four-factor solution provided constructs that were less complex than those in the five-factor solution, with acceptable indexes: $\chi^{2}(816, N=2792)=$ $56,593.41, p<.001$; Tucker Lewis Index $=.75$, RMSEA $=0.71$ (CI.90 $=.06$ to .07 ).

For the interpretation of the four factors, we used principal component analysis with a varimax solution. Our primary purpose was to select items for their utility as indicators of the anticipated factors underlying the MCQ, that is, their content, convergent and discriminant validity (Izquierdo et al. 2014). Several recognized criteria were used. First, we used a cut-off of .30 for the inclusion of an item in the interpretation of a factor. Overall, 14 items were eliminated from the four hypothesized factors based on the initial structure of the MCQ $(5,8$ and 1, respectively, from the first three factors; no item from the fourth factor). Second, the Kaiser-Meyer Olkin measure of sampling accuracy was .95 , above the commonly recommended value of .60 , and Barlett's test of sphericity was significant $\left(\chi^{2}(465)=46,544.33\right.$, $p<.001)$. Third, the commonalities were all below .30, confirming that each item did not share common variance with other items. Fourth, Eigenvalues indicated that the four factors explained $18.5 \%, 16.9 \%, 10 \%$ and $9.6 \%$ of the variance, respectively, and a total of $54.93 \%$ of the variance overall. These 31 items were used in subsequent analysis.

\section{Structural equation modelling}

Next, we conducted confirmatory factor analysis (CFA), using EQS 6.1 (Bentler 2006), to investigate the construct validity of the MCQ further. Our aims were fourfold: first, to understand the relationship between these latent constructs (testing a four-factor oblique measurement model; model 1) and, second, to investigate whether the four-factor oblique model could be modelled as a second-order, hierarchical factor, generating a fifth general latent factor. This fifth general factor would capture the shared covariances of the four loworder factors representing teachers' attitudes directly (factor 5; structural model 2). The third is to test whether model 2 was valid across eleven different countries and, finally, to examine the contribution of four demographic variables, namely, education level, teachers' age, number of children in the class and percentage of multilingual children in class on Teachers' Attitudes (F5) (model 3). In model 3, the analysis was based on the structural model emerging from model 2 , including only the latent variables.

In evaluating the goodness-of-fit of the models to the data, we adhered to the following criteria: Comparative Fit Indices (CFI) greater than .95 and Root Mean Square Errors of Approximation (RMSEA) below .06 (Byrne 2006; Hu and Bentler 1999). Finally, we allowed pairs of residual (error) variances to covary to improve the fit of the models. These correlations were suggested by the EQS modification indices and represent measurement error held in common by some of the items of the scale.

First, we evaluated the fit of the measurement model testing the inter-correlations and factor structure of the set of items with the pooled data from all the eleven countries participating in the study. The model 1 results are shown in Fig. 1. Standardized path coefficients are presented. This measurement model fit the entire dataset from all the participating countries well, $\chi^{2}(387, N=2792)=2757.20, p=.001 ; \mathrm{CFI}=.96$; $\mathrm{RMSEA}=.05$ (CI.90 $=.04$ to .05$)$. As 
expected, each item correlated significantly with its corresponding factor. Thus, the results support the originally hypothesized four-factor structure for scoring the Multilingual Classroom Questionnaire 4 .

Second, we captured the shared covariances of the four first-order variables through a fifth general, second-order factor, namely, Teachers' Attitudes (F5). The model 2 indices indicated that this second-order structural model was also good fitting, $\chi^{2}(381, N=2792)=2538.03$, $p=.001 ; \mathrm{CFI}=.96$; RMSEA $=.05$ (CI.90 = .03 to .04$)$. Moreover, a careful look at the factor loadings (Fig. 2) suggests that all four first-order factors accounted significantly for the portion of variance explained in F5. Model 2 produced a $\Delta \chi^{2}$ that had a statistically significant better fit to the data than model $1(p<.001)$, and thus, it was used in further analysis.

Third, to establish the consistency of model 2 in 11 different cultures, we conducted a factorial invariance analysis (Vandenberg and Lance 2000). The objective was to examine the degree to which the structure of model 2 was valid across countries, namely, yielding an identical factor structure. Establishing consistency across different countries would allow using model 2 to test the contribution of various demographic variables on teachers' attitudes. Measurement invariance was tested at the least constrained level, the configural level (Meredith 1993). Configural invariance is satisfied when the same pattern of fixed and free factor loadings is invariant across groups. Analysis showed that the model had a good fit in all eleven countries, $\chi^{2}(10, N=2792)=$ 28.16, $p<.01$; CFI $=.99$; RMSEA $=.07$ (CI.90 = .05 to .08) with the pattern of fixed and free parameters being equivalent. This result indicated that the five-factor structure model was invariant across the 11 countries, representing teachers' attitudes toward multilingualism in classrooms across the European countries participating in the study.

Finally, we examined the contribution of four demographic variables, namely, education level, teachers' age, number of children in class and percentage of multilingual children in class on teachers' attitudes (F5) (model 3). The results are shown in Fig. 3. The model 3 fit the data well $\chi^{2}(18, N=2792)=293.87, p<.001 ; \mathrm{CFI}=.95$; RMSEA $=.06($ CI.90 $=.06$ to .08$)$. As can be seen in Fig. 3, the relative magnitude of the standardized coefficients showed that teachers' attitudes yielded as a second-order latent variable and was significantly and negatively predicted predominantly by the number of children in the class.

\section{Comparisons of the four lower-order latent factors by country, gender or education level}

We examined possible group differences by country, gender or education level (elementary vs. secondary) on the original four factors emerging from the MCQ. Three MANOVA analyses were performed with the groups as a fixed factor and the four factors of the MCQ as the dependent variables. For this analysis, we estimated factor scores summing the raw scores corresponding to all items loading on a factor ${ }^{5}$. Using this method allowed us to compute average scores, retain the scale metric and preserve the variation in the original data (Tabachnick and Fidell 2007), enhancing, in turn, the interpretation of the results.

Descriptive statistics on all four factors of the MCQ for each country separately and group comparisons are presented in Table 2. The analysis with the factors as the dependent measures indicated a significant main group effect, Pillai's Trace $^{6}=.255, F(40,11124)=18.90$, $p<.001, \eta^{2}=.06$. Subsequent univariate ANOVAs indicated that the main effect of groups was significant for all four factors, namely, views on multilingualism $(\mathrm{F} 1)$ : $F(10,2781)=$ $38.23, p<.001, \eta^{2}=.12$; first language of migrant children (F2): $F(10,2781)=38.03, p<.001$, $\eta^{2}=.12$; L2 acquisition (F3): $F(10,2781)=39.90, p<.001, \eta^{2}=.13$; and literacy (F4): $F(10$, 


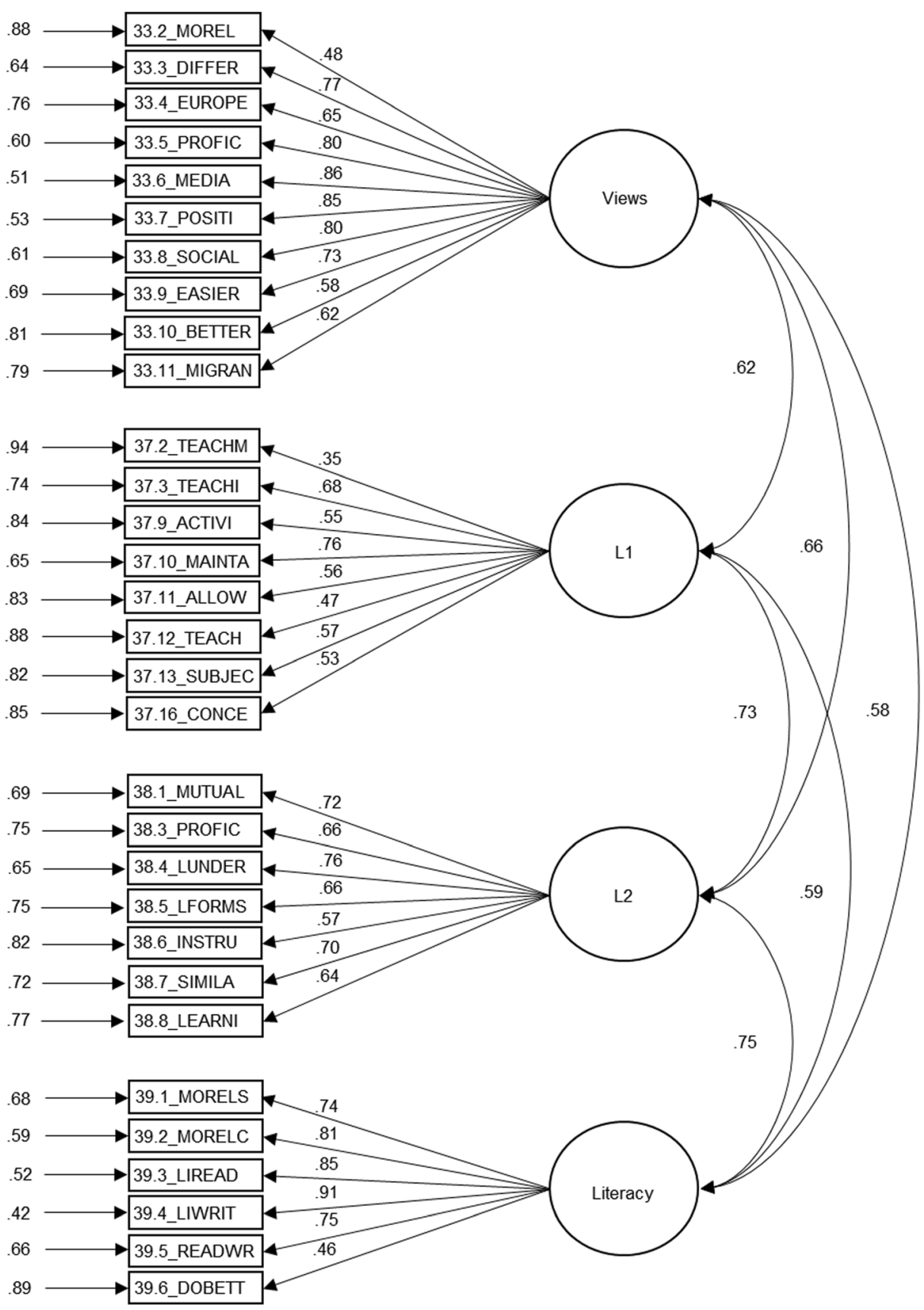

Fig. 1 The measurement model of the Multilingual Classroom Questionnaire (MCQ; Model 1). The squares represent observed variables. The circles represent the latent MCQ variables of views on multilingualism (F1), first language of migrant children (F2), L2 acquisition (F3) and literacy (F4), at first order. Coefficients are presented in standardized form. The parameter values for the measurement model are as follows: $\chi^{2}(387, N=$ $2792)=2757.20, p=.001 ; \mathrm{CFI}=.96 ; \mathrm{RMSEA}=.05(\mathrm{CI} .90=.04$ to .05$)$. Abbreviations for variables can be found in the APPENDIX based on the item number (the first two digits correspond to the main section of the MCQ; the latter digits correspond to the item under that section) 


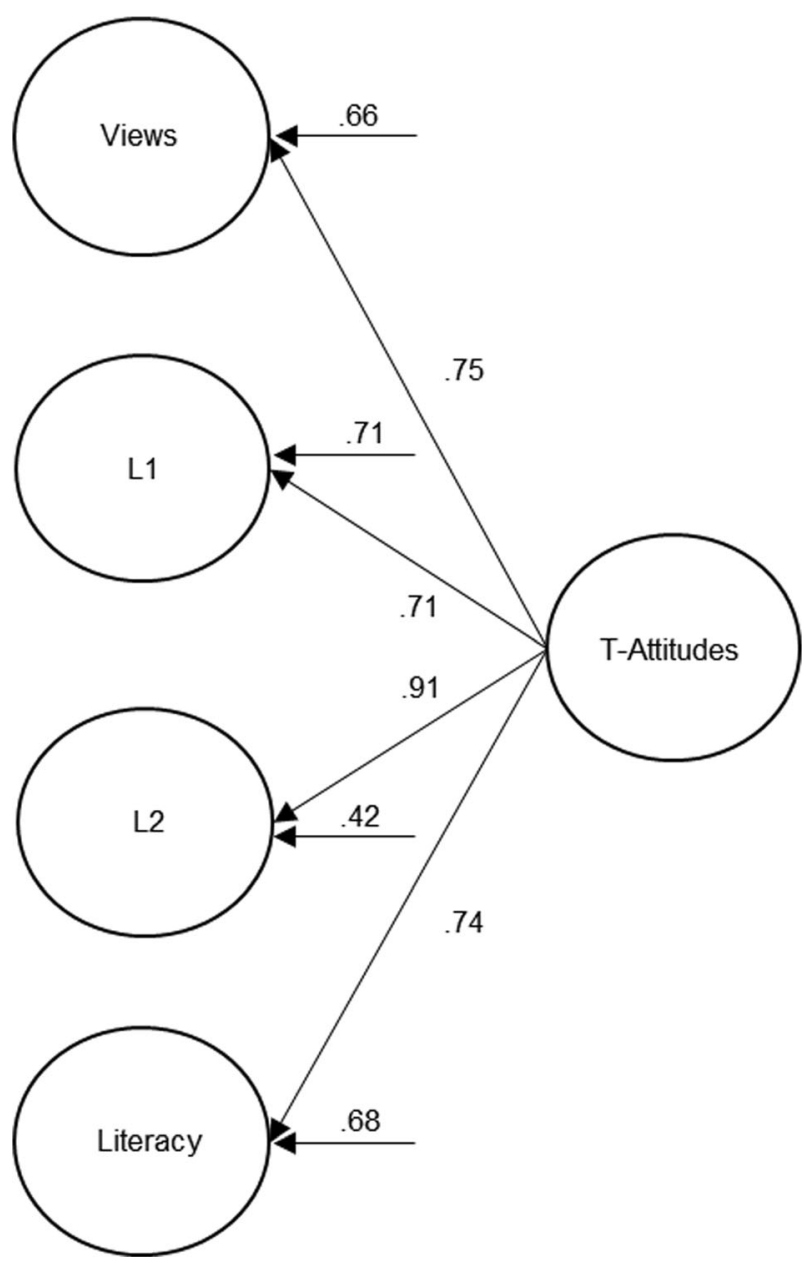

Fig. 2 The second-order structural model of the Multilingual Classroom Questionnaire (MCQ; Model 2). The circles represent the latent MCQ variables of views on multilingualism (F1; views), first language of migrant children (F2; L1), L2 acquisition (F3; L2) and literacy (F4), at first order and the teachers' attitudes (F5; TAttitudes) at second order. Coefficients are presented in standardized form. The parameter values for the measurement model are as follows: $\chi^{2}(381, N=2792)=2538.03, p=.001$; CFI $=.96$; RMSEA $=.05$ (CI.90= .03 to .04$)$

2781) $=17.44, p<.001, \eta^{2}=.06$. Post hoc tests using Bonferroni adjustment for multiple comparisons, tested with type I error set at $.05^{7}$, showed distinct clusters of countries derived from each analysis. Generally, Austria, Denmark, Greece and Portugal (in all four factors), followed by Catalonia (Spain) and Malta (in factors 1, 3 and 4), were among the groups that scored toward the positive end of the scale. Bulgaria and Turkey moved mostly toward the negative end of the scale, forming another distinct cluster. Finally, Cyprus, the UK and Slovakia were positioned somewhere in between, indicating indecisiveness regarding their views about multilingualism in Europe.

Next, we examined possible group differences in all four factors on multilingualism by gender (Table 3 ) and then by education level (Table 4). The analysis indicated significant main group effects for gender, Pillai's Trace $=.010, F(4,2639)=6.95, p<.001, \eta^{2}=.01$. 


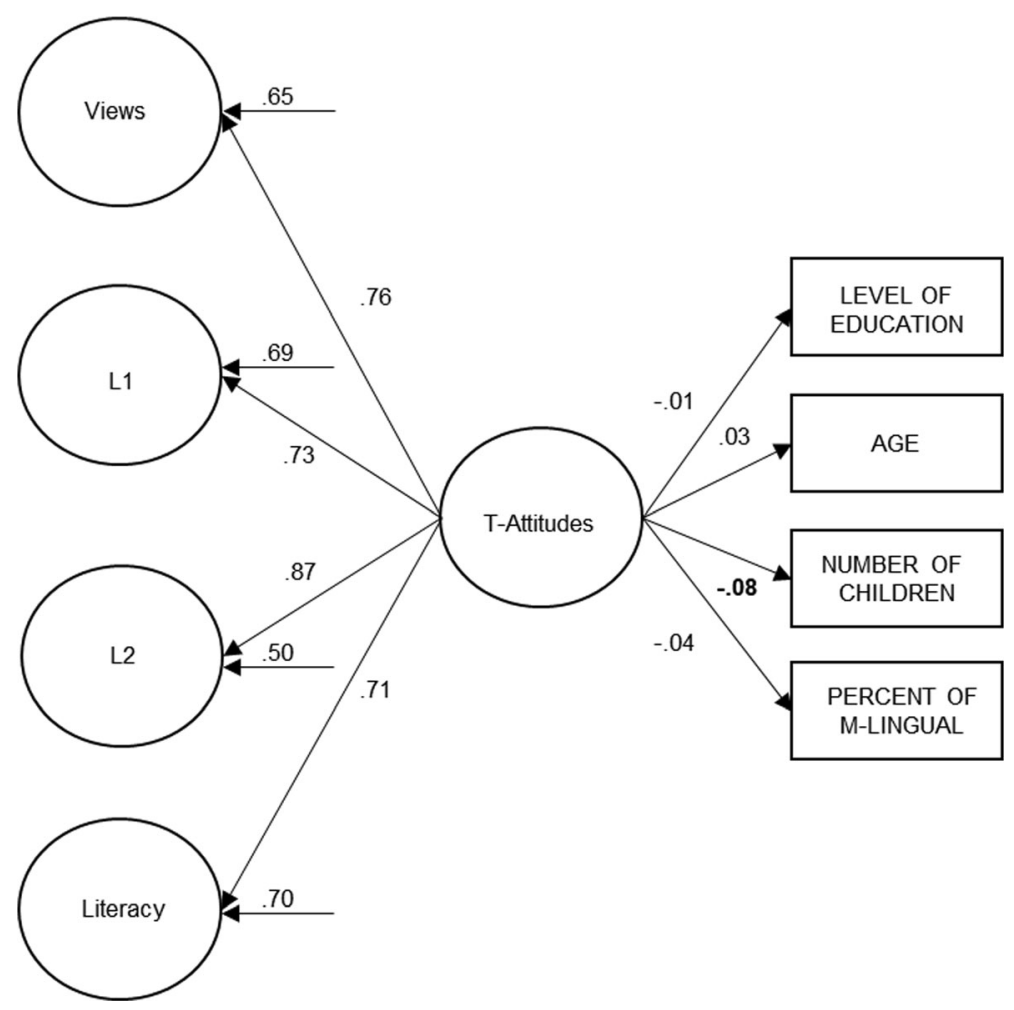

Fig. 3 Examining the contribution of demographic variables on teachers' attitudes (model 3). The circles represent the latent MCQ variables of views on multilingualism (F1; views), first language of migrant children (F2; L1), L2 acquisition (F3; L2) and literacy (F4), at first order and the teachers' attitudes (F5; T-Attitudes) at second order. The squares represent observed variables (the predictors for F5). Coefficients are presented in standardized form. The parameter values for the measurement model are as follows: $\chi^{2}(18, N=2792)=293.87$, $p<.001 ; \mathrm{CFI}=.95 ; \mathrm{RMSEA}=.06(\mathrm{CI} .90=.06$ to .08$)$

Subsequent univariate ANOVAs indicated that the main effect of group was significant only for $\mathrm{F} 1$, views on multilingualism, $F(1,2642)=14.09, p<.001, \eta^{2}=.01$, with the attitudes of the female teachers being significantly more positive than those of the male teachers $(p<.001)$. Finally, the main group effects of education level (elementary vs. secondary) were also significant, Pillai's Trace $=.008, F(4,2639)=5.26, p<.001, \eta^{2}=.01$. Subsequent univariate ANOVAs indicated that the main effect of groups was significant only for F2, first language of migrant children, $F(1,2642)=5.81, p<.05, \eta^{2}=.002$, with the attitudes of the elementary school teachers being significantly more positive than those of the secondary education colleagues $(p<.001)$. When both gender and education level entered the equation as fixed Factors, the effects of gender on F1-Views on multilingualism were retained. In contrast, the effects of education level were no longer significant.

\section{Discussion}

The linguistic diversity of learners in schools across Europe is significant, where teaching in a culturally diverse class is the norm. This diversity raises challenges for pupils, teachers and 


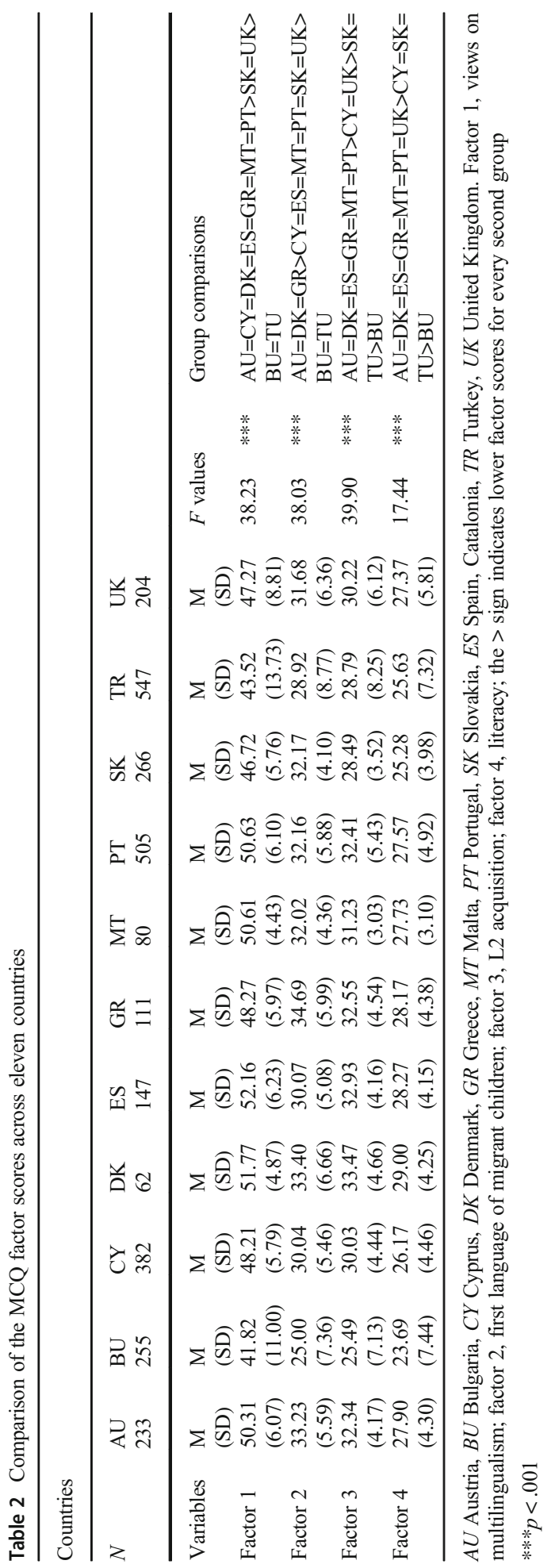


Table 3 Comparison of the MCQ factor scores by gender

\begin{tabular}{|c|c|c|c|c|}
\hline \multicolumn{5}{|l|}{ Gender } \\
\hline & Males $(n=684)$ & Females $(n=1960)$ & & \\
\hline Variables & $\begin{array}{c}\mathrm{M} \\
\text { (SD) }\end{array}$ & $\begin{array}{c}\mathrm{M} \\
(\mathrm{SD})\end{array}$ & $F$ values & \\
\hline Factor 1 & $\begin{array}{c}46.35 \\
(11.29)\end{array}$ & $\begin{array}{l}47.91 \\
(8.54)\end{array}$ & 14.09 & $* * *$ \\
\hline Factor 2 & $\begin{array}{l}30.90 \\
(7.18)\end{array}$ & $\begin{array}{l}30.49 \\
(6.82)\end{array}$ & 1.76 & \\
\hline Factor 3 & $\begin{array}{l}30.08 \\
(6.66)\end{array}$ & $\begin{array}{l}30.31 \\
(6.09)\end{array}$ & 0.68 & \\
\hline Factor 4 & $\begin{array}{l}26.60 \\
(5.95)\end{array}$ & $\begin{array}{l}26.60 \\
(5.59)\end{array}$ & 1.02 & \\
\hline
\end{tabular}

Factor 1, views on multilingualism; factor 2, first language of migrant children; factor 3, L2 acquisition; factor 4, literacy

$* * * p<.001$

policymakers. The current study developed a tool (MCQ) for use with teachers across Europe and provided the first initial comparative data across the European context. Respondents were predominantly from the primary school sector, female, middle-aged and with more than 6 years of teaching experience. The questionnaire reflected four different factors across the 11 countries: views on multilingualism, first language of migrant children, L2 acquisition and literacy. A fifth general factor that captured the shared covariances of the four low-order factors, thus, representing teachers' attitudes directly, was further identified. Some data from single countries have now been published in country-specific journals using the MCQ (Knudsen et al. 2020; Martins et al. 2019; Authors Mifsud \& Vella, 2018a, b). The current study advances our understanding of attitudes to multilingualism by examining the effects of country of origin, gender and education level in which the teachers taught (elementary vs. secondary) on the four factors emerging from the MCQ. Three aspects of the present findings contribute significantly to the existing literature.

Table 4 Comparison of the MCQ factor scores by education level

\begin{tabular}{lccc}
\hline Educational level & & & \\
& & & \\
& Elementary $(n=1435)$ & Secondary $(n=1209)$ & $F$ values \\
Variables & $\mathrm{M}$ & $\mathrm{M}$ & \\
& $(\mathrm{SD})$ & $(\mathrm{SD})$ & 2.76 \\
Factor 1 & 47.23 & 47.84 & 5.81 \\
& $(9.56)$ & $(9.08)$ & \\
Factor 2 & 30.89 & 30.24 & 0.93 \\
Factor 3 & $(6.91)$ & $(6.90)$ & \\
& 30.14 & 30.38 & \\
Factor 4 & $(6.15)$ & $(6.35)$ & 26.77 \\
& 26.40 & $(5.72)$ & \\
\hline
\end{tabular}

Factor 1, views on multilingualism; factor 2, first language of migrant children; factor 3, L2 acquisition; factor 4, literacy

$* p<.05$ 
We met our first objective by showing that teachers' attitudes about multilingualism in classrooms can be reliably measured across European countries using a carefully devised measurement tool. Previous studies have been country specific (Strobbe et al. 2017; Mary and Young 2018), so comparisons across European countries are now possible. The heterogeneity of both pupil and teacher variables allowed us to examine similarities and differences across country contexts. Despite the diversity in pupil and teacher variables, the results supported the originally hypothesized factors (teachers' views on multilingualism, the first language of the migrant children and L2 acquisition), including also a fourth factor (literacy) and a fifth general second-order factor as a function of all of the above. This structure not only provided further support to existing evidence about teachers' views on multilingualism (Strobbe et al. 2017) but also offered the necessary constructs to further elucidate factors at the individual or organizational level about multilingualism in schools. Particularly, the inclusion and emphasis on 'literacy' as a separate fourth dimension extended the latent dimensions related to the multilingualism construct. Necessary support to pre-service teachers is needed if highquality literacy courses are delivered to non-native speakers, as part of their regular teacher education curriculum (Lucas et al. 2008). Likewise, the generation of the fifth general factor allowed to test whether teachers' attitudes were invariant across countries, enabling an improved comprehension of how teachers' views on multilingualism interact with the first language of the migrant children, L2 acquisition and objective conditions of literacy to shape evaluations of how multilingualism shapes education in Europe.

Indeed, all four first-order factors accounted for a significant portion of variance explained in teachers' attitudes, in a second-order model. Thus, the MCQ represented teachers' attitudes toward multilingualism in classrooms across the European countries participating in the study. This finding adds value to the search for teachers' views about the role of multilingualism in the school, indicating that the latent constructs represented commonality among the constituent variables. Importantly, this representation did not differ across the cultures and contexts examined in the study, thus extending previous findings of the factors that influence teachers' attitudes toward multilingualism.

The numbers of children in the class, but not the percentage or the diversity of the pupils in their classes (Krueger 1999), markedly challenged teachers' views about multilingualism across the 11 countries. Neither languages spoken nor local contexts moderated the impact of numbers of children in the class on the teachers' attitudes. These findings challenge singlecountry studies that have highlighted the importance of the linguistic composition of the class on teacher perceptions (Strobbe et al. 2017) but further suggest in our comparative study that the number of children in the class was important. In smaller classes, there is more individualized teacher support for learning (Blatchford et al. 2002). Smaller class sizes significantly enhance achievement for children, especially minority children (Krueger 2003; Rothstein and Mishel 2002). Given the teachers reported concerns about large class sizes, one way to support the performance of second language learners in larger classes is by having the students work in small groups and teaching the students to work effectively in these small groups (Coelho 2012). This means ensuring that everyone has a turn in speaking, knows how to seek clarification, and for teachers provides the context for supporting vocabulary acquisition and the development of grammatical structures. Our findings provide additional evidence to the argument that teachers' views about multilingualism were primarily influenced by environmental factors such as the class size and not the teachers' self-reported ability to respond to the challenges related to the diverse language environments. Such structural factors are modifiable. 
Educational level (primary or secondary), another contextual variable, was also significant when group differences in the original four factors were explored. A significant difference was evident for first language of migrant children, with secondary teachers raising more concerns about the diversity of language backgrounds than primary school teachers. Secondary schools, with a more academic focus and structured curriculum, may limit teachers' abilities to include the pupils' home language in instructional contexts. Previous research has highlighted how the use of different languages in the classroom has been viewed as interference in instruction (García 2009). Indeed, evidence from the Netherlands indicates that secondary school teachers adhere to strong monolingual beliefs, which results in lower expectations of their multilingual pupils (Pulinx et al. 2017). Opportunities for informal use of the pupil's first language with teachers are also less frequent in secondary schools (Baker and Prys Jones 1998; Hickey et al. 2014). These results suggest an important avenue for further research.

When gender differences in the original four factors were explored, attitudes of the female teachers to multilingualism were significantly more favourable than those of the male teachers, but there were no significant differences for first language of migrant children, L2 acquisition or literacy (see Table 3). This finding may be explained by the female teachers' predominance within the primary sector where, as we have seen, they responded more positively about the first language of the migrant children. This finding does, however, concur with previous conclusions regarding the importance of the gender of teachers in education. A growing number of studies have documented the effect of teacher gender at the primary school (e.g. Winters et al. 2013; Antecol et al. 2015) or secondary school (e.g. Dee 2007; Winters et al. 2013) showing that having a female teacher improves students' educational outcomes, particularly in the elementary school. However, the mechanisms behind teacher-student gender interactions not only have limited empirical support but are beyond the scope of this paper. To the degree that the present findings are replicable, future research should interrogate the interactions between teacher-student gender, multilingual contexts and educational level.

In our study, the main effect of the country where teachers worked was also significant for all four factors, likely reflecting their geographical position, where there has been an unprecedented increase in the number of immigrants entering Europe since 2014 (Eurydice 2019). For example, in Catalonia, legislation is explicit about the actions to be taken for newcomers where specific protocols have been designed and implemented. Likewise, educational policy in Malta promotes bilingual education in all schools (Ministry for Education and Employment, Malta 2012, 2014, 2016). But these approaches are changing. Denmark has recently implemented a funded policy for bilingual children who need language support (Dagtilbudsloven, $\S 11,2019$ [Law about daycare]. Countries with more proactive approaches will be in a position to be more aware of and ready to respond to the challenges of multilingualism in classrooms, which we argue is reflected in their more positive attitudes.

On the other hand, countries with more traditional educational system (such as England) or lower population diversity (Slovakia, $3.77 \%$ foreign born populations) were more ambivalent in their views about multilingualism in Europe. These differences may reflect patterns of immigration, country policies or languages used in educational contexts, data that were not available to us in the survey. Future research should examine the extent to which these factors could explain differences in the teachers' views. For example, both the Slovak Republic and Turkey have low percentages of foreign-born individuals but a larger percentage of children who are late migrant arrivals, at or above the age of 12. Immigrant arrival in adolescence impacts performance (European Commission 2017), whereby students struggle more with the curriculum. This fact may affect both the teachers' views and their experiences. These late 
arrivals will, because of their age, enter the secondary school where, as we have seen, teachers were less positive about multilingualism. While these country differences are likely to reflect different social, educational and political standpoints, they highlight the importance of explicitly addressing broader factors that influence teachers' beliefs and practices (see Young 2014).

\section{Implications for policy and practice}

School settings are environments where children develop their social and cognitive competencies through oral and written language. It is here where children should make a strong start to learn the languages of schooling, and multilingual classrooms impact these learning environments. Structural variables influenced teachers' attitudes toward multilingual learners in our study these factors can be modified. Class size was a key feature, smaller classes positively impact the academic achievement of the children (e.g. Blatchford and Lai 2012), and our findings indicate that teachers also see this as key for multilingual students. It is likely that a change in the teacherstudent ratio, especially for urban areas where the ratio is high, will also decrease teachers' workload and make them more positive about teaching in multilingual contexts.

In the current study, there was preliminary evidence that secondary school teachers were particularly challenged. As such secondary schools are an important area to target in developing policy and practice related to multilingualism. Teacher education needs to address concerns related to using the first language in the bilingual classroom, developing a multilingual awareness (García 2008) and awareness of linguistically responsive teaching (Lucas et al. 2008). Such preparation provides different perspectives on creating an environment that is supportive and responsive to diversity, which can be made a resource for both individual children and the classroom.

\section{Limitations}

The cross-national nature of our study, while demonstrating many strengths, raised a range of challenges. Data were available for $11 \mathrm{EU}$ countries and, as such, cannot be generalized across the EU. Current detailed country characteristics, for example, educational policy, language(s) of instruction and immigrant population to identify other drivers of teachers' views, were not available. Nor have we distinguished between the teachers' personal and professional beliefs. Studies have indicated that while teachers' personal beliefs may not be as friendly and 'open' to the multicultural and multilingual student, their professional beliefs (and perhaps their inclass behaviour) is more open and acceptable (Pohan and Aguilar 2001; Resvani and Spinthouraki 2018). Despite these gaps, the demonstrated psychometric robustness of the measure provides a tool to explore these issues further.

Details are lacking of all the different languages of origins or social contexts that teachers were responding to. There is evidence that these impact on teachers' perceptions and may explain the small effect sizes found. Given the questionnaire format, we did not obtain data on individual children nor the practices used to meet the children's language learning needs. Comparative details at a more microanalytic level are clearly needed (Gogolin 2002). Nor were we able to collect data from children and parents, an additional important source of classroom contexts. Future work should consider addressing these limitations and developing new methodologies to examine these factors further.

Finally, despite attempts in many of the participating countries for the data to be representative of their populations, the study is not representative of teachers of 
multilingual classrooms across Europe. Participants were recruited through a general request to participate in a survey (either online or paper based) and were not stratified by location, type of school and teaching experience, for example. A more comprehensive and longitudinal perspective would provide further insights into how teachers develop their attitudes and strategies and how these differ between European countries and contexts.

\section{Conclusion}

It is clear that migration is having a significant impact on European classrooms. This, coupled with countries with more than one majority language, continues to raise significant challenges for teachers and pedagogy. Our data indicate that across Europe, this is a real opportunity to develop multilingual individuals who can use language appropriately in the classroom context. Policies of multilingual education should take into consideration teachers' beliefs and understandings. Our study demonstrated that teachers reliably identified the challenges presented by multilingual classes. Teachers require support to show 'sensitivity to contextual factors' (Palviainen and Mård-Miettinen 2015, p.397) when considering which language strategies to adopt. Results of the current study suggest that comparisons across countries using similar metrics are not only possible but have the potential to inform policy and practice.

Author's contribution All authors contributed to the conceptualization and design through a series of European meetings. J. E. Dockrell led on the conceptualization of the research, organization of the study and drafting the paper. T. C. Papadopoulos led on all the data analyses, and C. L. Mifsud led on the draft questionnaire protocol. All other authors were responsible for the data collection from their relevant countries.

Funding This project was funded by COST ACTION IS 1401 - the European Literacy Network and results from a collaboration across all Work Group 1 members and the leadership of a steering group (https://www. is1401eln.eu/en/working-groups/working-group-1/).

Data availability Data are available on request from T. C. Papadopoulos.

${ }^{1}$ In some European countries, there is more than one official language of instruction.

2 Turkish data obtained from the World Bank

3 The Expectation-Maximization (EM) algorithm is a two-step iterative approach and a method often used with multiple imputation to estimate the parameters in a model for incomplete data. This approach includes two steps that help find maximum likelihood estimates. The expectation iteration allows finding the distribution for the missing data based on the known values for the observed data and the current estimates of the parameters. The maximization iteration substitutes the missing data with the expected values. The EM algorithm is a suitable method for SEM analysis and when data are missing at random (e.g. Lin 2010). It helps preserve the relationship that a variable had with other variables in the dataset.

${ }^{4}$ This analysis aimed to the parsimony of factors' description. To ensure that the extracted factors based on the set of items included in the MCQ can be thought to represent a random sample from a set of underlying dimensions, we examined the factor structure with additional jackknife resampling or bootstrapping analysis techniques. Specifically, first, we divided the total sample into two equal subgroups. Next, we ran the exploratory factor analysis with the first group and the confirmatory factor analysis using the second group. The results were similar to the analysis reported in the text with the total sample. The Velicer's MAP test recommended a threefactor solution, and the Parallel Analysis recommended a four-factor solution for the MCQ items. Again, when we compared the two solutions, the four-factor solution provided a better fit than that of the three-factor solution, with acceptable indexes: $\chi^{2}(465, N=1394)=23057.02, p<.001$; Tucker Lewis Index $=.83$, RMSEA $=0.70$ $(\mathrm{CI} .90=.06$ to .07$)$. Likewise, the measurement model fit the second dataset well, $\chi 2(465, N=1394)=1612.33$, $p=.001 ; \mathrm{CFI}=.96 ; \mathrm{RMSEA}=.05(\mathrm{CI} .90=.04$ to .05$)$. Additionally, we ran a cluster analysis and estimated the 
factor and cluster analyses' congruence coefficient on the first group's four-factor solution (Revelle 2020). The purified alpha was .94

${ }^{5}$ The sum score method is usually desirable when the scales used to collect the original data are untested and exploratory (Hair et al. 2006, p. 140). To maximize the validity of the analyses, we also examined group differences using Bartlett factor scores. This refined method produces unbiased estimates of the true factor scores (for further discussion, see DiStefano et al. 2009). The findings on group comparisons were similar to those obtained from the analysis performed applying the non-refined sum score method.

${ }^{6}$ We report Pillai's Trace value instead of the Wilk's Lambda because the observed covariance matrices of the dependent variable were not equal across groups (Box's test was significant at $p<.001$ in all three MANOVAs).

${ }^{7}$ In the absence of any empirical findings supporting a specific hypothesis about the direction of an effect, we tested the null hypotheses with two-sided alpha level.

Open Access This article is licensed under a Creative Commons Attribution 4.0 International License, which permits use, sharing, adaptation, distribution and reproduction in any medium or format, as long as you give appropriate credit to the original author(s) and the source, provide a link to the Creative Commons licence, and indicate if changes were made. The images or other third party material in this article are included in the article's Creative Commons licence, unless indicated otherwise in a credit line to the material. If material is not included in the article's Creative Commons licence and your intended use is not permitted by statutory regulation or exceeds the permitted use, you will need to obtain permission directly from the copyright holder. To view a copy of this licence, visit http://creativecommons.org/licenses/by/4.0/.

\section{References}

Antecol, H., Eren, O., \& Ozbeklik, S. (2015). The effect of teacher gender on student achievement in primary school. Journal of Labor Economics, 33(1), 63-89. https://doi.org/10.1086/677391.

Bahr, N., \& Mellor, S. (2016). Building quality in teaching and teacher education. Camberwell, Australia: ACER Press.

Baker, C., \& Prys Jones, S. (1998). Encyclopedia of bilingualism and bilingual education. Clevedon: Multilingual Matters.

Bentler, P. M. (2006). EQS 6 structural equations program manual. Encino, CA: Multivariate Software, Inc..

Blatchford, P., \& Lai, K. C. (2012). Class size: Arguments and evidence. In B. McGraw, E. Baker, \& P. P. Peterson (Eds.), International encyclopedia of education (3rd ed.). Oxford, UK: Elsevier.

Blatchford, P., Moriarty, V., Edmonds, S., \& Martin, C. (2002). Relationships between class size and teaching: A multimethod analysis of English infant schools. American Educational Research Journal, 39(1), 101-132.

Bleses, D., Hojen, A., Justice, L. M., Dale, P. S., Dybdal, L., Piasta, S. B., et al. (2018). The effectiveness of a large-scale language and preliteracy intervention: The SPELL randomized controlled trial in Denmark. Child Development, 89(4), e342-e363. https://doi.org/10.1111/cdev.12859.

Byrne, B. M. (2006). Structural equation modeling with EQS: Basic concepts, applications, and programming (2nd ed.). Mahwah, NJ: Lawrence Erlbaum Associates.

Civitillo, S., Juang, L. P., \& Schachner, M. K. (2018). Challenging beliefs about cultural diversity in education: A synthesis and critical review of trainings with pre-service teachers. Educational Research Review, 24, 67-83. https://doi.org/10.1016/j.edurev.2018.01.003.

Coelho, E. (2012). Language and learning in multilingual classrooms: A practical approach. Multilingual Matters.

De Angelis, G. (2011). Teachers' beliefs about the role of prior language knowledge in learning and how these influence teaching practices. International Journal of Multilingualism, 8(3), 216-223. https://doi.org/10. 1080/14790718.2011.560669.

de Boer, H., Timmermans, A. C., \& van der Werf, M. P. C. (2018). The effects of teacher expectation interventions on teachers' expectations and student achievement: Narrative review and meta-analysis. Educational Research and Evaluation, 24(3-5), 180-200. https://doi.org/10.1080/13803611.2018.1550834.

De Houwer, A. (2007). Parental language input patterns and children's bilingual use. Applied PsychoLinguistics, 28(3), 411-424. https://doi.org/10.1017/S0142716407070221.

Dee, T. S. (2007). Teachers and the gender gaps in student achievement. Journal of Human Resources, 42(3), 528-554. https://doi.org/10.3368/jhr.xlii.3.528.

DiStefano, C., Zhu, M., \& Mîndrilă, D. (2009). Understanding and using factor scores: Considerations for the applied researcher. Practical Assessment, Research \& Evaluation, 14, 1-11. 
Ellis, E. M. (2004). The invisible multilingual teacher: The contribution of language background to Australian ESL teachers' professional knowledge and beliefs. International Journal of Multilingualism, 1(2), 90-108. https://doi.org/10.1080/14790710408668181.

European Commission. (2015). Language teaching and learning in multilingual classrooms. https://doi.org/10. $2766 / 766802$.

European Commission. (2017). Migrants in European Schools: learning and maintaining languages. DirectorateGeneral for Education, Youth, Sport and Culture Directorate B - Youth, Education and Erasmus, Schools and Multilingualism eu European Commission B-1049 Brussels. http://publications.europa.eu/resource/ cellar/c0683c22-25a8-11e8-ac73-01aa75ed71a1.0001.01/DOC_1.

Eurostat. (2018). Europe 2020 indicators - poverty and social exclusion. https://ec.europa.eu/eurostat/statisticsexplained/index.php/Europe_2020_indicators_-_poverty_and_social_exclusion.

Eurydice. (2017). Key data on teaching languages at school in Europe. Brussels: Eurydice.

Eurydice. (2019). Integrating Students from Migrant Backgrounds into Schools in Europe: National Policies and.

García, O. (2008). Multilingual language awareness and teacher education. In N. H. Hornberger (Ed.), Knowledge about language: Encyclopedia of language and education (pp. 385-400). New York: Springer.

García, O. (2009). Bilingual education in the 21st century: A global perspective. Malden, MA/Oxford: Basil/ Blackwell.

García, O., \& Hesson, S. (2015). Translanguaging frameworks for teachers: Macro and micro perspectives. In A. Yiacoumetti (Ed.), Multilingualism and language in education: Current sociolinguistic and pedagogical perspectives from commonwealth countries (pp. 221-242). Cambridge: Cambridge University Press.

Gathercole, V. C. M., \& Thomas, E. M. (2009). Bilingual first-language development: Dominant language takeover, threatened minority language take-up. Bilingualism-Language and Cognition, 12(2), $213-237$. https://doi.org/10.1017/s1366728909004015.

Geerlings, J., Thijs, J., \& Verkuyten, M. (2018). Teaching in ethnically diverse classrooms: Examining individual differences in teacher self-efficacy. Journal of School Psychology, 67, 134-147. https://doi.org/10.1016/j. jsp.2017.12.001.

Gogolin, I. (2002). Linguistic and cultural diversity in Europe: A challenge for educational research and research and practice. European Educational Research Journal, 1(1), 123-138. https://doi.org/10.2304/eerj.2002.1.1.3.

Hair, J. F., Black, W. C., Babin, B. J., Anderson, R. E., \& Tatham, R. L. (2006). Multivariate data analysis (6th ed.). Upper Saddle River, NJ: Pearson Education Inc..

Hattie, J. A. C. (2009). Visible learning: A synthesis of over 800 meta-analyses relating to achievement. London: Routledge.

Haukås, A. (2016). Teachers' beliefs about multilingualism and a multilingual pedagogical approach. International Journal of Multilingualism, 13(1), 1-18. https://doi.org/10.1080/14790718.2015.1041960.

Heller, M. (1999). Linguistic minorities and modernity: A sociolinguistic ethnography. London: Longman.

Hickey, T., Lewis, G., \& Baker, C. (2014). How deep is your immersion? Policy and practice in welsh-medium preschools with children from different language backgrounds. International Journal of Bilingual Education and Bilingualism, 17(2), 215-234. https://doi.org/10.1080/13670050.2013.866629.

Hu, L. T., \& Bentler, P. M. (1999). Cut-off criteria for fit indexes in covariance structure analysis: Conventional criteria versus new alternatives. Structural Equation Modeling: A Multidisciplinary Journal, 6(1), 1-55.

Izquierdo, I., Olea, J., \& Abad, F. J. (2014). Exploratory factor analysis in validation studies: Uses and recommendations. Psicothema, 26(3), 395-400. https://doi.org/10.7334/ psicothema2013.349.

Kim, L. E., Jorg, V., \& Klassen, R. M. (2019). A meta-analysis of the effects of teacher personality on teacher effectiveness and burnout. Educational Psychology Review, 31(1), 163-195. https://doi.org/10.1007/s10648018-9458-2.

Kirsch, C. (2018a). Dynamic interplay of language policies, beliefs and pedagogy in a preschool in Luxembourg. Language and Education, 32(5), 444 461. https://doi.org/10.1080/09500782.2018.1487452.

Kirsch, C. (2018b). Young children capitalising on their entire language repertoire for language learning at school. Language Culture and Curriculum, 31(1), 39-55. https://doi.org/10.1080/07908318.2017.1304954.

Klassen, R. M., \& Kim, L. E. (2019). Selecting teachers and prospective teachers: A meta-analysis. Educational Research Review, 26, 32-51. https://doi.org/10.1016/j.edurev.2018.12.003.

Knudsen, H., Donau, P., Mifsud, C., Papadopoulos, T., \& Dockrell, J. (2020). Multilingual classrooms—-danish teachers' practices, beliefs and attitudes. Scandinavian Journal of Educational Research. https://doi.org/10. 1080/00313831.2020.1754903.

Krueger, A. B. (1999). Experimental estimates of education production functions. The Quarterly Journal of Economics, Volume, 114(2), 497-532. https://doi.org/10.1162/003355399556052.

Krueger, A. B. (2003). Economic considerations and class size. The Economic Journal, 113, 34-63. https://doi. org/10.1111/1468-0297.00098. 
Lee, J. S., \& Oxelson, E. (2006). "It's not my job": K-12 teacher attitudes toward students' heritage language maintenance. Bilingual Research Journal, 30(2), 453-477. https://doi.org/10.1080/15235882.2006. 1016288 .

Lin, T. H. (2010). A comparison of multiple imputation with EM algorithm and MCMC method for quality of life missing data. Quality and Quantity, 44(2), 277-287. https://doi.org/10.1007/s11135-008-9196-5.

Linan-Thompson, S., Lara-Martinez, J. A., \& Cavazos, L. O. (2018). Exploring the intersection of evidencebased practices and culturally and linguistically responsive practices. Intervention in School and Clinic, 54(1), 6-13. https://doi.org/10.1177/1053451218762574.

Lucas, T., Villegas, A. M., \& Freedson-Gonzalez, M. (2008). Linguistically responsive teacher education: Preparing classroom teachers to teach English language learners. Journal of Teacher Education, 59(4), 361-373.

Madeira, A. (Coord.) (2015). Avaliação de impacto e medidas prospetivas para a oferta do Português Língua Não Materna (PLNM) no sistema educativo português. Lisboa: Mec. Malta and Gozo. Retrieved from http:// education.gov.mt/en/Documents/Literacy/ENGLISH.pdf.

Martins, M. A., Sousa, O., Castro, S. L., Dockrell, J., Papadopoulos, T., \& Mifsud, C. (2019). Views from Portuguese teachers on multilingualism and educational practices in multilingual classrooms. Analise Psicologica, 37(4), 493-506. https://doi.org/10.14417/ap.1622.

Mary, L., \& Young, A. (2018). Parents in the playground, headscarves in the school and an inspector taken hostage: Exercising agency and challenging dominant deficit discourses in a multilingual pre-school in France. Language Culture and Curriculum, 31, 318-332. https://doi.org/10.1080/07908318.2018.1504403 Measures. Eurydice report. Luxembourg: Publications Office of the European Union.

Meredith, W. (1993). Measurement invariance, factor analysis and factorial invariance. Psychometrika, 58(4), 525-543.

Mifsud, C.L. \& Petrova, R. (2017). Multilingual Classroom Questionnaire (MCQ), Centre for Literacy, University of Malta/European Literacy Network COST Action IS1401.

Mifsud, C. L., \& Vella, L. (2018a). Teacher agency and language mediation in two Maltese preschool bilingual classrooms. Language, Culture and Curriculum, 31(3), 272-288 Routledge. https://doi.org/10.1080/ 07908318.2018.1504400.

Mifsud, C. L. \& Vella, L. (2018b). To mix languages or not? Preschool bilingual education in Malta. In Mila Schwartz (Ed.) Preschool bilingual education. Agency in interaction between children, teachers and parents (pp. 57-98). Springer USA.

Ministry for Education and Employment, Malta. (2012). The National Curriculum Framework for All.

Ministry for Education and Employment, Malta. (2014). A National Literacy Strategy for all in.

Ministry for Education and Employment, Malta. (2016). A Language Policy for the Early Years.

O'Connor, B. P. (2000). SPSS and SAS programs for determining the number of components using parallel analysis and Velicer's MAP test. Behavior Research Methods, Instrumentation, and Computers, 32(3), 396-402.

OECD. (2018). The resilience of students with an immigrant background: Factors that shape well-being. Paris: OECD Publishing.

Otwinowska, A. (2014). Does multilingualism influence plurilingual awareness of Polish teachers of English? International Journal of Multilingualism, 11(1), 97-119. https://doi.org/10.1080/14790718.2013.820730.

Palviainen, A., \& Mård-Miettinen, K. (2015). Creating a bilingual pre-school classroom: The multilayered discourses of a bilingual teacher. Language and Education, 29(5), 381-399. https://doi.org/10.1080/ 09500782.2015.1009092.

Pianta, R. C., Belsky, J., Vandergrift, N., Houts, R., \& Morrison, F. J. (2008). Classroom effects on children's achievement trajectories in elementary school. American Educational Research Journal, 45(2), 365-397. https://doi.org/10.3102/0002831207308230.

Pohan, C. A., \& Aguilar, T. E. (2001). Measuring educators' beliefs about diversity in personal and professional contexts. American Educational Research Journal, 38, 159-182.

Pulinx, R., Van Avermaet, P., \& Agirdag, O. (2017). Silencing linguistic diversity: The extent, the determinants and consequences of the monolingual beliefs of Flemish teachers. International Journal of Bilingual Education and Bilingualism, 20(5), 542-556.

Ramos, F. (2009). California/Spain visiting teachers program participants' opinions about the use and effects of students' primary languages in the classroom. International Multilingual Research Journal, 3(2), 51-71. https://doi.org/10.1080/19313150903073430.

Reljic, G., Ferring, D., \& Martin, R. (2015). A meta-analysis on the effectiveness of bilingual programs in Europe. Review of Educational Research, 85(1), 92-128. https://doi.org/10.3102/0034654314548514.

Resvani, V., \& Spinthouraki, J.-A. (2018). Teachers' beliefs about diversity in the school classrooms and factors affecting it. In G. Nikolaou, S. Tsesmeli, K. Malafantis, \& I. Dimakos (Eds.), Proceedings of the $11^{\text {th }}$ Panhellenic Conference "Basic and Continuing Education of Teachers in Complex and Changing Environment" (pp. 897-902). Patras: Hellenic Educational Society Retrieved from http:/curriculum.gov.mt/en/resources/the-ncf/pages/default.aspx. 
Revelle, W. (2020). An introduction to the psych package: Part 2 Scale construction and psychometrics. https:// cran.rproject.org/web/packages/psychTools/vignettes/overview.pdf.

Rolstad, K., Mahoney, K., \& Glass, G. V. (2005). The big picture: A meta-analysis of program effectiveness research on English language learners. Educational Policy, 19(4), 572-594. https://doi.org/10.1177/0895904805278067.

Rosiers, K., Van Lancker, I., \& Delarue, S. (2018). Beyond the traditional scope of translanguaging comparing translanguaging practices in Belgian multilingual and monolingual classroom contexts. Language \& Communication, 61, 15-28. https://doi.org/10.1016/j.langcom.2017.11.003.

Rothstein, R., \& Mishel, L. (2002). The class size debate. Economic Policy Insitute.

Sebba, M. (2010). Societal bilingualism. In R. Wodak, B. Johnstone, \& P. Kerswill (Eds.), The SAGE handbook of sociolinguistics (pp. 445-459). Los Angeles, London: SAGE.

Seidel, T., \& Shavelson, R. J. (2007). Teaching effectiveness research in the past decade: The role of theory and research design in disentangling meta-analysis results. Review of Educational Research, 77(4), 454-499. https://doi.org/10.3102/0034654307310317.

Strand, S., Malmberg, L., \& Hall, J. (2015). English as an Additional Language (EAL) and educational achievement in England: An analysis of the National Pupil Database. Retrieved from London: https://v1. educationendowmentfoundation.org.uk/uploads/pdf/EAL_and_educational_achievement2.pdf.

Strobbe, L., Van Der Wildt, A., Van Avermaet, P., Van Gorp, K., Van den Branden, K., \& Van Houtte, M. (2017). How school teams perceive and handle multilingualism: The impact of a school's pupil composition. Teaching and Teacher Education, 64, 93-104.

Tabachnick, B. G., \& Fidell, L. S. (2007). Using multivariate statistics (5th ed.). Boston: Allyn \& Bacon.

Tong, F., Lara-Alecio, R., Irby, B., Mathes, P., \& Kwok, O. M. (2008). Accelerating early academic oral English development in transitional bilingual and structured English immersion programs. American Educational Research Journal, 45(4), 1011-1044. https://doi.org/10.3102/0002831208320790.

Vandenberg, R. J., \& Lance, C. E. (2000). A review and synthesis of the measurement invariance literature: Suggestions, practices, and recommendations for organizational research. Organizational Research Methods, 3(1), 4-70.

Vandenbroucke, L., Spilt, J., Verschueren, K., Piccinin, C., \& Baeyens, D. (2018). The classroom as a developmental context for cognitive development: A meta-analysis on the importance of teacher-student interactions for children's executive functions. Review of Educational Research, 88(1), 125-164. https://doi. org/10.3102/0034654317743200.

Wenger, E. (1998). Communities of practice: Learning, meaning, and identity. New York: Cambridge University Press.

Winters, M. A., Haight, R. C., Swaim, T. T., \& Pickering, K. A. (2013). The effect of same-gender teacher assignment on student achievement in the elementary and secondary grades: Evidence from panel data. Economics of Education Review, 34, 69-75. https://doi.org/10.1016/j.econedurev.2013.01.007.

Young, A. S. (2014). Unpacking teachers' language ideologies: Attitudes, beliefs, and practiced language policies in schools in Alsace, France. Language Awareness, 23(1-2), 157-171. https://doi.org/10.1080/ 09658416.2013.863902.

Zauche, L. H., Thul, T. A., Mahoney, A. E. D., \& Stapel-Wax, J. L. (2016). Influence of language nutrition on children's language and cognitive development: An integrated review. Early Childhood Research Quarterly, 36, 318-333. https://doi.org/10.1016/j.ecresq.2016.01.015.

Publisher's note Springer Nature remains neutral with regard to jurisdictional claims in published maps and institutional affiliations.

Julie E. Dockrell, Director of Centre for language, literacy and numeracy: research and practice UCL, Institute of Education. j.dockrell@ucl.ac.uk

Current themes: language learning and difficulties, barriers to learning at school.

1. Dockrell, J. E. (2019). Language learning challenges in the early years. The SAGE Handbook of Developmental Psychology and Early Childhood Education. SAGE Publications Limited.

2. Joye, N., Broc, L., Olive, T., \& Dockrell, J. E. (2019). Spelling Performance in Children with Developmental Language Disorder: A Meta-Analysis across European Languages. Scientific Studies of Reading. doi: https://doi. org/10.1080/10888438.2018.1491584

3. Arfe, B., Dockrell, J. E., \& De Bernardi, B. (2016). The effect of language specific factors on early written composition: the role of spelling, oral language and text generation skills in a shallow orthography. READING AND WRITING, 29 (3), 501-527. doi: https://doi.org/10.1007/s11145-015-9617-5

Timothy C. Papadopoulos, Department of Psychology and Center for Applied Neuroscience, University of Cyprus, 1 University Ave., 2019, Aglantzia, Nicosia, Cyprus, papadopoulos.timothy@ucy.ac.cy 
Current themes: learning disabilities and their treatment and specifically on (a) all aspects of reading development and dyslexia (development, cognition, and pathology),

1. Papadopoulos, T. C., Georgiou, G. K., Deng, C., \& Das, J. P. (2018). The structure of speed of processing across cultures. Advances in Cognitive Psychology, 14, 112-125.

2. Papadopoulos, T. C., Kendeou, P., \& Spanoudis, G. (2012). Investigating the factor structure and measurement invariance of phonological abilities in a sufficiently transparent language. Journal of Educational Psychology, 104, 321-336.

3. Georgiou, G. K., Parrila, R. K., \& Papadopoulos, T. C. (2008). Predictors of word decoding and reading fluency in English and Greek: A cross-linguistic comparison. Journal of Educational Psychology, 100, 566580 .

Charles Mifsud, Director for the Centre of Literacy University of Malta.

Center for Literacy, University of Malta, Msida MSD2080, Malta. charles.1.mifsud@um.edu.mt

Current themes: curriculum theory, educational technology, teaching methods.

1. Mifsud, C.L. \& Vella, L. (2018) Teacher agency and language mediation in two Maltese preschool bilingual classrooms, In Language, Culture and Curriculum, 31 (3), 272-288 Routledge https://doi.org/10.1080/ 07908318.2018 .1504400

2. Mifsud, C. L. \& Vella, L. (2018) To mix languages or not? Preschool bilingual education in Mata. In Mila Schwartz (Eds.) Preschool bilingual education. Agency in interaction between children, teachers and parents (pp. 57-98). Springer USA

3. Mifsud, C. L. \& Petrova, Z. (2018) Literacy education in the digital age. In Barzillai, M., Thomson, J., Schroeder S. \& van den Broek, P. Learning to read in a digital world (pp. 165-184). John Benjamins, Netherlands

Lorna Bourke, Department of Psychology, Liverpool Hope University, Hope Park, Liverpool, L16 9JD. bourkel@hope.ac.uk

Current themes: cognitive and developmental psychology.

1. Bourke, Lorna and Davies, Simon J. and Sumner, Emma and Green, Carolyn (2014) Individual differences in the development of early writing skills: testing the unique contribution of visuo-spatial working memory. Reading and Writing, 27 (2). pp. 315-335. ISSN 1573-0905

2. Bourke, Lorna and Bamber, Philip M. and Lyons, Minna (2012) Global citizens: Who are they? Education, Citizenship and Social Justice, 7 (2). pp. 161-174. ISSN 1746-1979

3. Bourke, Lorna and Adams, Anne-Marie (2012) Is it difference in cognitive resources and language skills that make girls better writers? Journal of Writing Research, 3 (3). pp. 249-277. ISSN 2030-1006

Olga Soler-Vilageliu, Department de Psicologia Bàsica, Transmedia Catalonia Group, Universitat Autònoma de Barcelona, Cataloni, Spain. Olga.soler@uab.cat

Current themes: Psycholinguistics and cognitive processing.

1. Kandel, S. and Soler, O. (2010). Differential syllable effects when learning to write French and Catalan words, Current psychology letters [Online], Vol. 25, Issue 3, 2009| 2010, Online since 08 July 2010, connection on 09 May 2020. URL: http://journals.openedition.org/cpl/496

2. Soler, O. \& Kandel, S. (2009). Programación del trazo en la escritura infantil: importancia de la estructura silábica. Infancia y Aprendizaje, 32(2), 189-198.

Susanne Seifert University of Graz, Austria, Merangasse 70/2, 8010 Graz, Susanne.seifert@uni-graz.at,

Current themes: Primary education, Language education, special education.

1. Paleczek, L., Seifert, S. and Gasteiger-Klicpera, B. (2017), Influences on teachers' judgement accuracy of reading abilities on second and third grade students: A multilevel analysis. Psychol. Schs., 54: 228-245. doi: https://doi.org/10.1002/pits.21993

2. Seifert, S., Kulmhofer, A., Paleczek, L. et al. Suggestions for Vocabulary Focused Reading Lessons for Mainstream Classrooms Addressing Both L1 and L2 Learners. Early Childhood Educ J 45, 333-345 (2017). https://doi.org/10.1007/s10643-015-0762-x

3. Schwab, S., Seifert, S. \& Gasteiger-Klicpera. B. (2014) Improving reading in children with German as a first or second language, International Journal of Early Years Education, 22:2, 210-222, DOI: https://doi.org/10. 1080/09669760.2014.909308

Edvina Bešić, University of Graz, Austria, Merangasse 70/2, 8010 Graz, edvina.besic@uni-graz.at,

Current themes: inclusive education.

1. Bešić, E., Paleczek, L. \& Gasteiger-Klicpera, B. (2020) Do not forget about us: attitudes toward the inclusion of refugee children with(out) disabilities, International Journal of Inclusive Education, 24:2, 202,217, https:// doi.org/10.1080/13603116.2018.1455113

2. Bešić, E. Paleczek, L. Rossmann, P., Krammer, M. \& Gasteiger-Klicpera, B. (2020) Attitudes toward inclusion of refugee girls with and without disabilities in Austrian primary schools, International Journal of Inclusive Education, 24:5, 463-478, DOI: https://doi.org/10.1080/13603116.2018.1467976 
Barbara Gasteiger-Klicpera, University of Graz, Austria, Merangasse 70/2, 8010 Graz, Barbara.gasteigerklicpera@uni-graz.at,

Current themes: language acquisition, language learning, language education.

1. Breyer, C, Wilfling, K., Leitenbauer, C. \& Gasteiger-Klicpera, B. (2019) The self-efficacy of learning and support assistants in the Austrian inclusive education context, European Journal of Special Needs Education, DOI: https://doi.org/10.1080/08856257.2019.1706255

2. Krammer, M., Gasteiger-Klicpera, B., Holzinger, A. \& Wohlhart, D. (2019) Inclusion and standards achievement: the presence of pupils identified as having special needs as a moderating effect on the national mathematics standards achievements of their classmates, International Journal of Inclusive Education, DOI: https://doi.org/10.1080/13603116.2019.1573938

3. Krammer, M., Rossmann, P., Gastager, A. \& Gasteiger-Klicpera, B. (2018) Ways of composing teaching teams and their impact on teachers' perceptions about collaboration, European Journal of Teacher Education, 41:4, 463-478, DOI: https://doi.org/10.1080/02619768.2018.1462331

A. Ralli, Department of Psychology, School of Philosophy, University of Athens, University Campus, Ilisia 157 84, Greece.

Current themes: cognitive development, language acquisition, language difficulties.

1. Ralli, A. Melpomeni, S Tsiatsiou, A. (2017). Language and Psychosocial Skills of Institutionalized Children in Greece, TOFAMS, 9, 76-87, DOI: https://doi.org/10.2174/1874922401709010076

2. Ralli, A. M., Polychroni, F., Lampi, K. (2016). Language and learning skills of Roma and no-Roma students

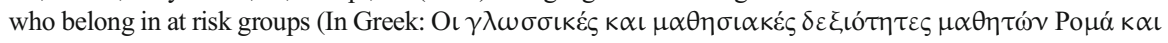

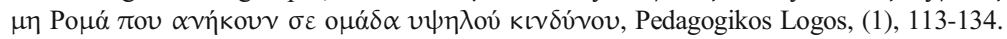

3. Ralli, A. (2016). The Impact of Contextual Factors on Response Patterns of Novel Word Pairings. Universal Journal of Psychology 4.6 (2016) 261-269. doi: https://doi.org/10.13189/ujp.2016.040603.

I Dimakos, Dept. of Education \& Social Work, University of Patras, Patras, GR-26500 Greece.

Current themes: children's developing writing, resilience, assessment.

1. Dimakos, I. C., \& Petropoulos, A. (2014). The role of knowledge and interest on the narrative writing of elementary school children Research Paper presented at the Writing Research Across Borders III Conference, 18-22 February 2014, Paris, France.

2. Dimakos, I. C., \& Papakonstantinopoulou, A. (2012). Resilience and self-efficacy in elementary school children. Epistimoniki Epetirida PTDE (Scientific Annual Review Dept of Primary Education, University of Ioannina) 24, 68-90. [in Greek].

3. Dimakos, I. C., \& Papakonstantinopoulou, A. (2012). Providing psychological and counselling services to Roma students: A preliminary report for a three-year longitudinal project. In P. Cunningham \& N. Fretwell (Eds.), Creating communities: Local, national and global (pp. 94-103). London

S. Karpava. University of Cyprus, Department of English Studies, 75 Kallipoleos, P.O. Box 20,537, 1678, Nicosia, Cyprus. karpava.sviatlana@ucy.ac.cy

Current themes: bilingualism, multilingualism.

1. Karpava, S. (2019). Heritage Language Acquisition in Cyprus: Longitudinal and Cross-Sectional Analysis. In Guijarro-Fuentes, P. and C. Suárez-Gómez (eds.) Language Acquisition and DevelopmentProceedings of GALA 2017. Cambridge Scholars Publishing: Newcastle upon Tyne, UK, pp. 403-425. ISBN 1527524418, 9,781,527,524,415

2. Karpava, S., Ringblom, N. and Zabrodskaja, A. (2018). Language Ecology in Cyprus, Sweden and Estonia: Bilingual Russian-Speaking Families in Multicultural Settings. Journal of the European Second Language Association, 2 (1), 107-117, https://doi,org/10.22599/jesla.41

3. Ioannou, E. and Karpava, S. (2018). Anxiety effect on productive and perceptive skills teaching in EFL classrooms in Cyprus. Proceedings of the 2nd International Conference: "Literacy and Contemporary Society: Spaces, Discourses, Practices» 28-29 November 2017, "Filoxenia" Conference Centre, Nicosia, Cyprus, pp. 552-565.

Martins ISPA-Instituto Universitário, Lisbon, Portugal mmartins@ ispa.pt

Current themes: literacy, language education.

1. Martins, M. A., Sousa, O., Castro, S. L., Dockrell, J., Papadopoulos, T., \& Mifsud, C. (2019). Views from Portuguese teachers on multilingualism and educational practices in multilingual classrooms. Analise Psicologica, 37 (4), 493-506. doi: https://doi.org/10.14417/ap.1622.

2. Alves-Martins, M., Salvador, L., \& Fernández, M. M. (2017). “Otro niño lo escribió as'́'. Ayuda educativa y resultados de actividades de escritura inventada. Revista de Educación, 377, 161-186. doi: https://doi.org/10. 4438/1988-592X-RE-2017-377-357

3. Albuquerque, A., \& Alves-Martins, M. (2016). Promotion of literacy skills in early childhood: a follow-up study from kindergarten to Grade. Infancia y Aprendizaje, 39(3), 592-625. doi: https://doi.org/10.1080/ 02103702.2016.1196913 
Otília Sousa Polytechnic Institute of Lisbon and University of Lisbon, otilias@ eselx.ipl.pt

Current themes: literacy, language learning.

1. Costa, T., Sousa, O. e Cardoso, A. (2015). Compreensão na Leitura num manual de Estudo do Meio. Da Investigação às Práticas: Estudos de natureza educacional, 5 (I), 98-117.

2. Sousa, O. C. (2014). Literacia, desenvolvimento linguístico e textual. In Santos, A.C., Gonçalves, A., Sequeira, P. \& Salvado, T. (Org.). Intercompreensão, Plurilinguismo \& Didática das Línguas. (pp. 211-227). Chamusca: Cosmos.

3. Sousa, O.C. (2014) O Ditado como estratégia de aprendizagem, EXEDRA, 9, 116-127.

Susanne Castro, University of Porto, Portugal slcastro@fpce.up.pt

Current themes: Teacher Education.

1. Martins, M. A., Sousa, O., Castro, S. L., Dockrell, J., Papadopoulos, T., \& Mifsud, C. (2019). Views from Portuguese teachers on multilingualism and educational practices in multilingual classrooms. Analise Psicologica, 37 (4), 493-506. doi: https://doi.org/10.14417/ap.1622.

Hanne B. Søndergaard Knudsen, Center for Developmental \& Applied Psychological Science (CeDAPS), Aalborg University hannebsk@hum.aau.dk,

Current themes: language impairment, working memory, executive function.

1. Knudsen, H. B. S., Pedersen, T. P., Engelbrekt, P., \& Jensen de López, K. (2019). Spirende voksne med risiko for at udvikle komplicerede sorgreaktioner: Et feasibility-studie. Psyke \& Logos, 40(1), 165-182. https://doi. org/10.7146/pl.v40i1.115090

2. Søndergaard Knudsen, H. B., Jensen de López, K., \& Archibald, L. M. D. (2018). The contribution of cognitive flexibility to children's reading comprehension-The case for Danish. Journal of Research in Reading, 41(Suppl 1), S130-S148. https://doi.org/10.1111/1467-9817.12251

3. Jensen de López, K., Søndergaard Knudsen, H.B., \& Hansen, T. G. B. (2017). What is measured in bereavement treatment for children and adolescents? A systematic literature review. Illness, Crisis \& Loss, 28, 363-387. https://doi.org/10.1177/1054137317741713

Pernille Donau, Center for Developmental \& Applied Psychological Science (CeDAPS), Aalborg University pdonau@hum.aau.dk

Current themes: doctoral student.

1. Hanne B. Søndergaard Knudsen, Pernille S. Donau, Charles Mifsud, Timothy C. Papadopoulos \& Julie E. Dockrell (2020) Multilingual Classrooms_-Danish Teachers' Practices, Beliefs and Attitudes, Scandinavian Journal of Educational Research, DOI: https://doi.org/10.1080/00313831.2020.1754903

Belma Haznedar, Faculty of Education, Department of Foreign Language Education, 34,342 - Istanbul, Bogazici University, Turkey haznedab@boun.edu.tr

Current themes: migrants, language acquisition, second language learning.

1. Haznedar, B., Kreeft-Peyton, J. \& Young-Scholten, M. (2018). Teaching adult migrants: A focus on the languages they speak. Critical Multlingualism Studies: An Interdisciplinary Journal, 6 (1), 155-183.

2. Haznedar, B. \& Ketrez, F.N. (2016). The Acquisition of Turkish in Childhood. Amsterdam: John Benjamins Publishing Company.

3. Haznedar, B. (2007). The acquisition of tense - aspect in child second language English. Second Language Research, 23(4), 383-417. doi:https://doi.org/10.1177/0267658307080330

Marina Mikulajová, Comenius University, Tomášikova 20, 82102 Bratislava, Slovak Republic marina.mikulajova@paneurouni.com

Current themes: literacy, preliteracy, language abilities.

1. Caravolas, M.; Lervåg, A.; Mikulajová, M., Defior, S.; Seidlová Málková, G.; \& Hulme, C. (2019). A crosslinguistic, longitudinal study of the foundations of decoding and reading comprehension ability. Scientific Studies of Reading, Online First. doi: https://org/https://doi.org/10.1080/10888438.2019.1580284

2. Marková, J., Cséfalvay, Zs., Mikulajová, M., Schöffelová, M. Analýza porozumenia viet v slovenčine. Test porozumenia viet s normami. Bratislava: Univerzita Komenského v Bratislave, 2015. 177 s. ISBN 978-80223-3797-7

3. Franke, H., \& Mikulajová, M. (2012). Pre-literacy skills of Slovak children with various profiles of language abilities. Pedagogika, LXII, 1(2), 164-177. Dissemnination of Slovak ELDEL outputs among Czech language pathologists, psychologists and special educators.

Nina Gerdzhikova, University of Plovdiv, Department of Pedagogy and Psychology, Bulgaria. gerdni7@yahoo.de Current themes: not available.

1. Gerdzhikova, N. (2018). Attitudes of Bulgarian teachers to multilingualism depending on the level of education. EPH - International Journal of Educational Research (ISSN: 2208-2204), 2(12), 01-08. Retrieved from https:/ephjournal.org/index.php/er/article/view/993

2. Gerdzhikova, N. (2013). Überprüfung einer Wörterliste für die prozessualle Diagnostik der emotionalen Befindlichkeit von 13-jährigen im Unterricht. In: сб. Психология: Проблемы практического применения (II), под ред. Г.А.Койнова, Чита, стр. 72-81 
3. Gerdzhikova, N. (2013). Emotionale Befindlichkeit von Schülern in dem Unterrichtsprozess - erste Überprüfung eines Fragebogens für die Selbstbeurteilung. In: сб.Педагогическое мастерство (III), Отв.ред.Г.А.Кайнова, Москва, стр. 57-60.

\section{Affiliations}

J. E. Dockrell ${ }^{1} \cdot$ T. C. Papadopoulos ${ }^{2} \cdot$ C. L. Mifsud ${ }^{3} \cdot$ L. Bourke $^{4} \cdot$ O. Vilageliu ${ }^{5} \cdot$ E.

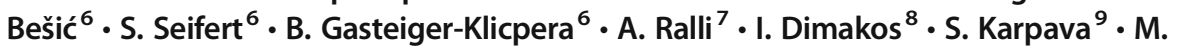
Martins $^{10} \cdot$ O. Sousa ${ }^{11} \cdot$ S. Castro ${ }^{12} \cdot$ H. B. Søndergaard Knudsen ${ }^{13} \cdot$ P. Donau ${ }^{13} \cdot$ B. Haznedar $^{14} \cdot$ M. Mikulajová ${ }^{15} \cdot$ N. Gerdzhikova ${ }^{16}$

T. C. Papadopoulos papadopoulos.timothy@ucy.ac.cy

C. L. Mifsud charles.1.mifsud@um.edu.mt

L. Bourke bourkel@hope.ac.uk

O. Vilageliu

Olga.soler@uab.cat

S. Seifert

Susanne.seifert@uni-graz.at

B. Gasteiger-Klicpera

Barbara.gasteiger-klicpera@uni-graz.at

A. Ralli
asralli@psych.uoa.gr
I. Dimakos
idimakos@upatras.gr

S. Karpava

karpava.sviatlana@ucy.ac.cy

M. Martins

mmartins@ispa.pt

O. Sousa

otilias@eselx.ipl.pt

S. Castro

slcastro@fpce.up.pt

H. B. Søndergaard Knudsen hannebsk@hum.aau.dk

P. Donau

pdonau@hum.aau.dk

B. Haznedar

haznedab@boun.edu.tr

M. Mikulajová

marina.mikulajova@paneurouni.com 
N. Gerdzhikova

gerdni7@yahoo.de

1 Institute of Education Centre for Language, Literacy and Numeracy: Research and Practice, UCL, London, UK

2 Department of Psychology and Center for Applied Neuroscience, University of Cyprus, 1 University Ave., Aglantzia, Nicosia, Cyprus

3 Center for Literacy, University of Malta, Msida MSD2080, Malta

4 Department of Psychology, Liverpool Hope University, Hope Park, Liverpool L16 9JD, UK

5 Department de Psicologia Bàsica, Transmedia Catalonia Group, Universitat Autònoma de Barcelona, Cataloni, Spain

6 University of Graz, Merangasse 70/2, 8010 Graz, Austria

7 Department of Psychology, School of Philosophy, University of Athens, University Campus, 15784 Ilisia, Greece

8 Dept. of Education \& Social Work, University of Patras, GR-26500 Patras, Greece

9 Department of English Studies, University of Cyprus, 75 Kallipoleos, P.O. Box 20537, 1678 Nicosia, Cyprus

10 Instituto Universitário, Lisbon, Portugal

11 Polytechnic Institute of Lisbon, University of Lisbon, Lisbon, Portugal

12 University of Porto, Porto, Portugal

13 Center for Developmental \& Applied Psychological Science (CeDAPS), Aalborg University, Aalborg, Denmark

14 Faculty of Education, Department of Foreign Language Education, 34342 - Istanbul, Bogazici University, Istanbul, Turkey

15 Comenius University, Tomášikova 20, 82102 Bratislava, Slovak Republic

16 Department of Pedagogy and Psychology, University of Plovdiv, Plovdiv, Bulgaria 